\title{
The Role of Science \& Technology in the Transition from a Centrally-Planned Economy to a Market Economy in the Czech Republic
}

\author{
Greg Tegart
}

The transition from a central planned economy to a market economy in Central and Eastern European countries has had significant impacts on the national research systems of these countries and on academia-industry relations and the innovation process. Müller (1995) has discussed the general aspects of the impact of the transition in a number of these countries and concludes that there are ongoing major changes in resource inputs accompanied by increased mobility of research manpower and by adaptation of research institutes to survive in an environment of limited funding and increased competition. The changes have varied from country to country with the most radical changes occurring in the former German Democratic Republic and in the Czech Republic.

This article briefly renews the historical background to the present situation and focusses on the case of the Czech Republic.
The nations of Central \& Eastern Europe namely Poland, the former German Democratic Republic (East Germany), Czechoslovakia, Hungary, Romania, Bulgaria, Yugoslavia and Albania were under the hegemony of the former Soviet Union for a period of roughly 44 years following World War II. In this period the Soviet Union imposed its social, economic, ideological, political and scientific systems on these countries. These systems relied on central planning, political repression and excessive bureaucratic interference in civilian industries. Although the Soviet Union poured major resources into military technology, this hardly affected the nations of Central and Eastern Europe in the development of their technological capability.

The sweeping political changes at the end of the $80 \mathrm{~s}$ and early $90 \mathrm{~s}$ meant that these countries have had to face major economic changes resulting from the breakup of COMECON, the economic 
body that guided economic development and trade within the Soviet sphere of influence, together with pressure of competition from the countries of Western Europe, North America and Asia. Their inherited systems were not suitable for the needs of a market economy and they have been forced to look to a total restructuring of their systems. This restructuring has been accomplished with varying degrees of success in the eight countries.

It appears the history and culture of these countries has played a significant role in their ability to deal with the transition process. Thus the northern tier of four countries (East Germany, Poland, Czechoslovakia and Hungary) shared in the intellectual brilliance of the European Enlightenment of the 17th and 18th Centuries and of Vienna when it was the intellectual centre of the AustroHungarian empire during the late 19th and early 20th Centuries. This legacy of scientific freedom and academic excellence is a major reason that these nations still conduct world class research in some areas of science. These four have managed to cope reasonably well with the change process although East Germany is a special case because of reunification with West Germany in October 1990 and consequent access to massive amounts of funding to assist the transition. Even so the process there has been painful, both socially and economically.

The southern tier of four Balkan countries (Romania, Bulgaria, Albania and Yugoslavia) have not shared fully in the intellectual traditions of Central Europe, although they have been influenced by that tradition as well as by the oriental culture of the old Ottoman (Turkish) empire to the south. These four have coped less well with the change process, particularly Yugoslavia. They still retain many elements of the Soviet system, particularly politically and bureaucratically, and these are resisting change. As a consequence, they are in problems economically.

Table 1 lists the GDP/capita for these countries and suggests that the two tiers can be clearly differentiated with growth

Table 1: GDP/capita for Eastern and Central European Countries (US\$)'

\begin{tabular}{|lcc|} 
& 1991 & 1994 \\
\cline { 2 - 3 } Poland & 1830 & 2270 \\
Hungary & 2690 & 3840 \\
Czech Republic* $^{*}$ & 2289 & 3210 \\
Slovakia* & 1828 & 1900 \\
Bulgaria & & \\
Rumania & 2320 & 1160 \\
Albania & 1620 & 1120 \\
Yugoslavia & 623 & 360 \\
$\quad$ (Serbia \& Montenegro) & 3093 & 900 \\
\hline
\end{tabular}

* Czechoslovakia split into the Czech Republic and Slovakia in 1993. 
in the northern tier and decline in the southern tier (Europa World Year Book, 1995). Slovakia suffered more than the Czech Republic in the post-communist era due to the run-down of the armaments industry and heavy industry in general. Yugoslavia suffered from the break-up of the old Republic and the sanctions imposed against the Serbs.

\section{The Soviet System for R\&D and its Impacts on Eastern Europe}

An excellent discussion of the history of the Soviet R\&D system up to the present day has been given by Kaukonen (1994). We briefly review it here to understand its impact on Central and Eastern Europe (see also Müller, 1995a).

Following the Revolution of 1917, science in the Soviet Union was organised by the State to serve its techno-economic needs. A Soviet R\&D structure evolved in which the Academy of Sciences and its research institutes were mainly responsible for fundamental research, the institutes of the Government ministries were mainly responsible for applied R\&D related to the missions of these ministries, and the institutions of higher education were responsible for educating future scientists. In the Soviet Union, the sector split in terms of R\&D personnel in 1981. was approximately:

$\begin{array}{lr}\text { Academy of Science } & 9 \% \\ \text { Higher education institutions } & 35 \% \\ \text { Ministry R\&D institutes } & 50 \% \\ \text { Industry and administration } & 6 \%\end{array}$

Problems arose (and continue) because basic research was separated organisationally from applied R\&D; the institutions of higher education per- formed little research and their students thus obtained little experience in experimental science, the State-owned manufacturing sector which conducted little R\&D had little incentive to incorporate innovations from the research institutes into its production processes, and overall the system was highly militarised which resulted in a scarcity of resources for civilian $R \& D$. The result has been that the Soviets excelled in some areas of basic research and in much military and space science and technology while being unable to conduct much satisfactory civilian $R \& D$ or produce many state-ofthe-art civilian products, especially in areas like computers and consumer electronics (see Boesman, 1991).

This system was imposed on the Central and Eastern European countries after the take-over by Communist-led governments at the end of World War II. While it is difficult to assess expenditure on $R \& D$ in these countries because of the problems of the funding base, available data (Boesman, 1991; Müller, 1995a) suggest that the Soviet bloc expended more of their human resources and expenditure on $R \& D$ than the Western nations (Table 2), although how effectively this was utilised is a matter of speculation. Regionally Eastern Europe had strong $R \& D$ capabilities in mathematics, theoretical physics, materials research, life sciences, chemistry and mechanisms of chemical reactions.

The political climate of rejection of structures from the Communist regime after the change to democracy in 1990 has meant that much of the cultural and technological heritage has been deliberately destroyed. As a generalisation, the restructuring of the economies has resulted in the closing down of most of the 
Table 2: Selected R\&D Indicators for Eastern Europe and the Soviet Union (after Boesman, 1991)

\begin{tabular}{|lcccc|}
\hline & & $\begin{array}{c}\text { Scientists and } \\
\text { Engineers }\end{array}$ & $\begin{array}{c}\text { Scientists and } \\
\text { Engineers per } \\
\text { Million of Population }\end{array}$ & $\begin{array}{c}\text { R\&D Expenditure } \\
\text { per Gross National } \\
\text { Product (per cent) }\end{array}$ \\
US & $(1986)$ & 787400 & 3265 & 2.8 \\
Japan & $(1987)$ & 590700 & 4853 & 2.8 \\
UK & $(1986)$ & 98700 & 1748 & 2.4 \\
France & $(1986)$ & 105000 & 1898 & 2.3 \\
W Germany & $(1985)$ & 143600 & 2354 & 2.7 \\
E Germany & $(1987)$ & 125600 & 7574 & - \\
Poland & $(1987)$ & 42800 & 1133 & 4.5 \\
Czech & $(1987)$ & 64600 & 4161 & 4.3 \\
& & & & 2.7 \\
Hungary & $(1987)$ & 22300 & 2105 & 3.3 \\
Bulgaria & $(1987)$ & 50600 & 5641 & 3.8 \\
Yugoslavia & $(1987)$ & 33700 & 1445 & 5.1 \\
USSR & $(1987)$ & 1518000 & 5414 & \\
\hline
\end{tabular}

State-owned and operated industrial $R \& D$ institutions. The budget for the Academies of Science has been greatly reduced, providing for low salary levels for the researchers and very limited funds for new equipment and technology. Research money for academic institutions is also limited. As a consequence the R\&D expenditure per Gross National product figures of Table 2 have decreased substantially as noted by Müller (1995A). Thus in 1992, Poland was 0.92 per cent, Czech Republic was 1.87 per cent, Hungary was 1.13 per cent, Bulgaria was 1.35 per cent. These decreases have been accompanied by comparable decreases in R\&D manpower.

We will now consider the situation in the Czech Republic in more detail.

\section{The Impact of the Soviet Industry System on the Czech Republic}

Between the two world wars, Czechoslovakia was one of the leading industrialised countries in Europe, with products exported to world markets. The country promoted contacts with its strongest neighbour, Germany, which accounted for a fifth of Czechoslovakia's foreign trade. This made Germany its chief trading partner between the two world wars. In an effort to expand, Czechoslovak industries sought access to various foreign markets notably in southwestern Europe and the countries of southwest Asia. The share of the Soviet Union in Czechoslovakia's foreign trade then amounted to just one per cent. 
Sweeping change to industry structure and trade patterns occurred after the Communist takeover in 1948. Key priority was given to building the country's heavy industries, while the traditionally successful branches of the Czech consumer industries were scaled down. Metallurgy, heavy engineering, chemical production and many other industries consuming large amounts of energy and domestic or imported raw materials were the main growth industries. Although the overall volume of industrial output kept rising, Czechoslovakia's economic record steadily deteriorated compared with advanced Western countries (Holocek et al, 1995).

Within 40 years (1948-1988), the country's heavy industries increased their output 14-times, while the whole consumer sector registered a mere 8-fold rise. Growth in production was mostly secured by employing more workers and not by raising productivity of labour or employing new technologies. Such an expansion of heavy industries caused widespread damage to the environment, shortages of water, exploitation of highquality arable land for industrial purposes and similar negative ramifications. Most products were destined for the less competitive Eastern European markets. As a result, Czechoslovakia's heavy industries began losing what remained of their international reputation and credibility.

Associated with these changes in industry structure was a radical change in trade patterns. An overwhelming position was gained by the Soviet Union, whose share in the Czechoslovakian foreign trade rose to 44 per cent in the 1980s. In addition to military hardware, Czechoslovakia exported primarily metallurgical products, heavy machinery, trucks and locomotives; also twothirds of its footwear production, large quantities of clothing and textile products, beer and various foodstuffs went to the Soviet Union. Of particular significance were deliveries of Czech uranium for the Soviet nuclear program. With the establishment of COMECON, roughly four fifths of Czechoslovakia's foreign trade was conducted with its member states notably with East Germany, Poland and Hungary. Coupled with this change in industry structure and trade pattern was a major change in the S\&T system to the Soviet model, as discussed earlier. This new system was built up to support the changed industry structure with a high State expenditure on $R \& D$ as noted in Table 2.

\section{The Transition to a Market Economy and its Consequences for Industry}

The disintegration of the Soviet power bloc in 1990 was followed by the demise of COMECON with major financial consequences. The Czech Republic still has many of what are apparently non-recoverable claims in the former Soviet bloc countries. Most of the country's East European trading partners suffer from acute cash shortages, and the transforming Czech economy can hardly afford to grant long-term credits. Cash flow problems are hampering Czech imports of raw materials.

Sweeping structural changes have been introduced aimed at a speedy transition from central planning to a market economy. This is, however, a formidable task. The key precondition for changes is privatisation. The country's return to private ownership is being accom- 
plished by restoring property to the original owners, by the sale of property to domestic and foreign buyers, as well as non-traditional methods, such as the process of coupon privatisation in which shares of former State-owned industrial plants, companies and businesses are offered to Czech citizens. The transformation of ownership has been progressing very fast. The process of privatisation, which has already been completed in the service and business sectors, has advanced considerably in the building industry and is at full swing in industry and the health care system. Large-scale agricultural production seems most resistant to transformation.

Economic restructuring has led to changes in industrial production, and employment, as the industry structure has been changing to a more realistic one suited to the Czech Republic's size and resources. Thus the previously over- manned heavy industries have been down-sized eg. the Skoda group reduced numbers from 35000 to 20000 over the past six years. The changes in industrial production are shown in Table 3.

The change to an industry structure capable of competing internationally is leading to a major change in trading patterns away from the former Soviet Union. Thus in 1996, the European Union received 59 per cent of exports with the Federal Republic of Germany being the major market at 36 per cent. Exports to other economies in transition have dropped to 29.5 per cent with Slovakia being the major market at 14.2 per cent. Significant and growing foreign capital, eg. US $\$ 3.1$ billion in 1994, is flowing into the country. This has the advantage of bringing in new technology but the disadvantage of losing control of industries eg. the Skoda car company is now dominated by Volkswagen.

Table 3: Production Output in Selected Manufacturing Industries (after Müller, 1996) (1989 $=100 \%$, in \%, constant prices)

\begin{tabular}{|lcccc|}
\hline Industries & 1992 & 1993 & 1994 & $\begin{array}{c}1995 \\
\text { (as at June) }\end{array}$ \\
energy & 91 & 86 & 84 & 86 \\
fuels & 78 & 73 & 74 & 71 \\
ferrous metallurgy & 59 & 55 & 57 & 65 \\
machinery, electrotechnology & 50 & 45 & 43 & 46 \\
chemistry, rubber & 69 & 65 & 68 & 69 \\
wood processing & 66 & 59 & 61 & 66 \\
glass and ceramics & 73 & 67 & 71 & 78 \\
textile, leather & 55 & 49 & 48 & 49 \\
foodstuff processing & 73 & 71 & 69 & 70 \\
& & & & \\
\hline
\end{tabular}

Source: Statistical Year-book 1993, 1994. Figures for 1992-1994 cover enterprises with more than 25 employees 


\section{The Czech Nuclear Industry - A Victim of the Transition}

An excellent example of the problems faced by industry in the transition from a centrally planned to a market economy is the Czech nuclear industry. In common with other countries interested in the application of nuclear energy, Czechoslovakia set up a National Centre for Atomic Energy Research in 1955. This facility had a small research reactor LVR- 15 with a power output of $10 \mathrm{MW}$ and facilities for handling irradiated materials as well as equipment for neutron diffraction and for materials studies. Its first major activity was related to $R \& D$ for a gas cooled, heavy water moderated reactor. In 1971 the Institute was transferred to the Czechoslovak Atomic Energy Commission and its focus shifted to other reactor types and to applications of ionising radiation.

In the late 1970's, a decision was taken by COMECON to institute a nuclear power program in Central Europe to supplement the available sources of electricity mainly based on fossil fuels (see de la Ferte, 1991). A major motivation was to encourage energy self-sufficiency in the satellite countries in order to direct a larger share of Soviet oil exports to countries which could pay with hard currency. The USSR imposed its own reactor designs on its partners and maintained full control of the nuclear fuel cycle. With the exception of Romania which opted for the Canadian CANDU reactor design, all the other countries were equipped with Soviet VVER pressured light water cooled designs of 440 or 1000 megawatts.

A bilateral agreement was concluded between Czechoslovakia and the Soviet
Union for construction of VVER-440 reactors. Later this agreement was extended to production and delivery of equipment for nuclear power plants of the other Communist-controlled countries in the region. Production facilities were set up at the Skoda plant in Pilsen to produce equipment for the reactor proper, reactor auxiliaries and equipment for the concrete containing shaft. In the period 1980-1993, the company delivered 21 complete reactor sets of the VVER-40 type to plants in Hungary, Czechoslovakia, Poland and East Germany. A plant is currently in operation in the Czech Republic at Dukovany (4 x $440 \mathrm{MW}$ ) and supplies 21 per cent of the electricity of the Republic. Another is at Bohunice in Slovakia ( $2 \times 440 \mathrm{MW})$ while another is at Mochovce ( $4 \times 440 \mathrm{MW})$. These supply 54 per cent of the electricity for Slovakia.

A design for a larger reactor of 1000 MW (VVER-1000) was put into production for a new plant being built at Temelin (2 reactors) in the Czech Republic to replace several lignite stations which are being closed down for environmental reasons. Another two have been installed in Bulgaria but plans for a further two were shelved because of pressure from environmental groups on safety grounds. There are no new orders for reactors firstly because of lack of hard currency in countries of the region and secondly because of lack of confidence in Soviet reactor technology in Western countries following the Chernobyl accident. This has posed major problems for the Skoda plant which has been forced to reduce manpower substantially and to divert its equipment and skills to production of containers for storage and transport of spent fuel elements both for 
the Czech Power Company which operates the Czech plants and for export to Germany for storage of fuel elements of the VVER-440 reactors which are being decommissioned. If they do not receive any orders from other countries, the plant will gradually run-down and significant skills will be lost.

Over the period of the late 70 s and the 80 s, the Nuclear Research Institute was built up to provide support for the nuclear power program in Czechoslovakia and reached a peak of over 1000 personnel engaged in a variety of design studies, safety studies, environmental monitoring etc. With the transition to a market economy, the Institute has been transformed from a State-owned enterprise into a joint stock company over the past three years and in the process the staff has been reduced to 600 . After initial problems, the Institute is now running at a profit (roughly US\$ 0.75 million or 6 per cent return on sales). Income is roughly 40 per cent from the Czech Power Company, 16 per cent from other State contracts, 15 per cent from foreign contracts and the rest from other industry contracts (Nuclear Research Institute, 1995). The transition appears to have been completed successfully in this case and since the average life of a nuclear power plant is about 30 years, the Institute can look forward to a reasonable future, even if the Czech nuclear industry ultimately collapses.

\section{The Transformation of the R\&D System and its Implications}

A number of authors (Müller 1995a; Müller 1995b; Müller 1996; Provaznik et al 1996) have discussed in detail the transformation of the R\&D system in the
Czech Republic as a consequence of the transition. The Soviet model has been dismantled and is being replaced with a system suitable for a small country operating in a global market.

Thus the changes in industry structure noted earlier are reflected in a significant decline in industrial $R \& D$ as companies close down their in-house capability and rely on imported technology to produce competitive products. Further, industrial $R \& D$ is increasingly moving outside the country as multinationals rationalise their $R \& D$ activities in their acquisitions. Expenditure on industrial R\&D in 1994/94 was 0.99 per cent of GDP and declined to only 0.84 per cent in 1994/95.

This is reflected in a decline in industrial R\&D manpower are shown in Table 4 ; only the machinery and chemicals rubber sectors are maintaining a moderate $R \& D$ capability. This suggests problems at a future date since in small countries a few large firms, whether homebased or foreign-based, can have a considerable and disproportionate influence on the patterns of technological development because they are the main creators of new technologies. Experience shows that it is important to maintain a diversified economy for long term economic health since many firms operating in different areas maximise opportunities for innovation (Marceau, 1996). The creation of new innovative enterprises depends on the maintenance of an adequate level of $R \& D$ manpower.

The industrial research institutes have been restructured since they were overmanned for the needs of the smaller economy and industry of the new Czechoslovakia and then the Czech Re- 
Table IV: Industrial R\&D Manpower by Industry (after Müller, 1996)

\begin{tabular}{|lcc|}
\hline Manufacturing Branch & Manpower & $\mathbf{1 9 9 3 / 9 0 ( \% )}$ \\
fuel & 193 & 12.8 \\
ferrous metallurgy & 702 & 23.8 \\
chemicals and rubber & 2233 & 37.8 \\
machinery & $9568^{*}$ & 29.5 \\
electronics and electrotechnology industry & 2149 & 22.7 \\
glass and ceramics & 207 & 21.5 \\
wood processing industry & 78 & 11.6 \\
leather industry & 223 & 17.7 \\
textile industry & 91 & 5.4 \\
foodstuff industry & 223 & 19.8 \\
tool manufacturing & 16882 & 26.3 \\
\hline
\end{tabular}

* of which $48 \%$ in transport machinery (aero and car production)

Source:Czech Statistical Office;

public. The general pattern is that budgets were cut by about half with a consequent halving of manpower. A number have been privatised and are operating successfully in a contract mode, for example the Nuclear Research Institute, while others have been closed down. Similarly, the Institutes of the Academy of Science have been rationalised and downsized by roughly half. This has enabled them to be more effective by shedding inefficient political appointees. The former strong links with Russian research have been broken and increasingly the links with Western research are being strengthened. Links to EU Framework programs and to co-operative projects in Europe are being developed and there is an increasing interchange of researchers.

Under the Soviet model, the universities did little research since their major role was teaching as noted earlier. A feature of the reforms of the past few years has been the revival of university research. Thus university research has been stimulated by the setting-up of the Grant Agency of the Czech Republic in 1993 with competition for grants on a peer review basis. Young researchers are being particularly encouraged to stay in the Czech Republic, although salaries and grants are small by Western standards.

There are clearly problems in maintaining sufficient support for $R \& D$ as the Government struggles to maintain the pace of transformation to a market economy with a slowly growing economy and lowered industrial production. In 1993 the Government allocated only 0.40 per cent of GDP to R\&D; this increased marginally to 0.41 per cent in 1994. The total R\&D/GDP ratio for 1994 of 1.4 per cent places the Czech Republic well below the OECD average of 1.92 per cent (business 1.19 per cent, government and universities 0.71 per 
cent). This decline in R\&D poses problems for the future.

There are a number of important reasons why a flourishing $R \& D$ structure is essential for small countries if they are going to meet the objectives set by their governments for more competitive industry and wealth creation (Tegart, 1990):

1. It is difficult, if not impossible, to build up skills that are needed in a competitive industry if there is little $R \& D$ taking place. Even basic research not intended to have any immediate industrial applications can have an economically significant by-product in the training of postgraduate students and ancillary staff who contribute to the national aggregate skill base.

2. Not all imported technology is in a form suitable to the needs of many small countries. Skilled personnel are required who can understand notquite-appropriate technology and adapt it to local requirements.

3 . There are vital products unique to the local needs of small countries. Thus, in the Czech Republic, strong support is essential for the glass industry to develop into new applications and new materials.

4. There are aspects of the local environment that cannot be fully understood or managed without the maintenance of strong basic research capability. The remediation of the polluted environments resulting from mining and heavy industry is a major task for the Czech Republic.

5. Countries that contribute relatively small fractions of the world's scientific effort need local capacity to assess and tap into the world pool of scien- tific knowledge. This is particularly important in the new global knowledge economy.

6. Science and technology have a broader cultural and social significance for contemporary society as a major source of creativity and adaptability. The recognition of their cultural centrality may be a long-term prerequisite for the effective management of technological and economic change in contemporary societies.

\section{Conclusion}

There are no precedents for the transition from centrally planned to market economies taking place in Central and Eastern Europe. A spectrum of approaches is being used with some more successful than others. Thus the countries which had some history of links with the West and of periods of democratic government have coped better than those which moved from feudal societies into rigid centrally controlled states.

The consequences of the transition are significant for the industry structures of these countries and for the R\&D systems which have been built to support those industry structures. In general, heavy industries were developed with little concern for the environment and the legacy of pollution problems is immense while the industries themselves were energy and manpower intensive and lacked the modern technology of industries in the West. They are thus much less competitive and need major structural transformation in terms of downsizing, introduction of new technologies and financial restructuring and introduction of strategic management. 
A major problem is the lack of an innovative culture since it is now clearly recognised that technological innovation is essential for economic growth and social development of nations. Much has been written on innovation (Dodgson and Rothwell, 1994; Johnston, 1996) and it is clear that it is a complex process based on transfer of knowledge by formal and informal networks within a widely diversified group. At the firm level, there needs to be strong internal interaction together with close cxtcrnal alliances with suppliers, customers and financial backers. At the network level, the concept of a national system of innovation has been used to characterise the relationships between all those involved in the production, diffusion and use of new, economically useful knowledge. Each country has its unique national system and the success or otherwise of interaction between the players in the country is directly related to its pattern of economic growth.

The rigid boundaries of the Soviet R\&D structure clearly inhibited such interaction with adverse economic consequences. The challenge for the countries of Central and Eastern Europe is to move rapidly towards a new structure which will encourage interaction and innovation. Such a structure must recognise the need for wealth creation, the need to maintain competitiveness on a global scale and the need to ensure optimum linkages between research and commercialisation. While some moves have been made in the Czech Republic to link research and commercialisation (Müller, 1996a) there is clearly a need for a strategic national approach. So far the thrust has been driven by a 'bottom-up' approach from researchers in the Acad- emy of Sciences or the universities looking for links with existing industry or to creation of new industries. Thus research organisations have developed research parks or technology transfer centres in order to survive with declining resources. Müller (1996a) has given several case studies of successful enterprises of this type.

In many Western countries, it has been recognised that, while government, industry and universities all have their own roles to play, a new paradigm has emerged in the so-called 'Triple Helix' of government-industry-academic interaction (Etzkowitz and Leydesdorff, 1995). This model was originally called after the intertwined double helix of the DNA molecule but I believe that a better analogy is collagen which is a triple helix of three weak polypeptide chains which link together to produce a stronger whole.

The interaction is manifested in different ways in different countries but one excellent example from Australia is the establishment of Co-operative Research Centres in which researchers from industry, universities and government agencies work together to solve problems in agreed and focussed areas of research (Tegart, 1996). Currently 62 Centres are operating in the areas of manufacturing technology, information and communications technology, mining and energy, agriculture and ruralbased manufacturing, and environment. A recent review has concluded that the Co-operative Research Centre Program has significantly changed the research culture in Australia and produced a close interaction between industrial and academic researchers for the benefit of the country. The key to its 
success has been the provision by the Australian Government of guaranteed base funding for 7 years for successful consortia (selected by competition) provided that the funding is matched or bettered by contributions in cash or kind from the participants (universities, industry or Government research organisations). The current Government contribution is roughly US\$100 mill per year.

Researchers in the Czech Republic have expressed a keen interest in the Program, but clearly any move in this direction will need a significant input of government funding. It would clearly be impossible to fund a Program on the Australian scale at this stage of development of the Czech economy but a pilot scheme could be mounted given a strategic national approach to the challenge of developing an innovative industry structure able to compete in the global knowledge economy.

\section{Notes}

1 In June 1991 the author participated in a conference on "Harnessing Engineering and Technology for Economic Growth: Opening the Dialogue Between the Engineering Communities of the East and West" held in Budapest. This stimulated an interest in the problems of the research systems in the transition from centrally planned to market economies. A later visit to Hungary, an extended visit in the Czech Republic in mid 1996 and a further visit in 1997 have provided opportunities for data gathering and further discussion with officials and colleagues, particularly in the Engineering Academy of the Czech Republic.

\section{References}

Boesman, W C

1991 Eastern European and Soviet Science and Technology: Capabilities and Needs. Paper 91-114 SPR, Congressional Research Service, Washington, DC.

de la Ferte, J

1991 "A new role for nuclear energy". OECD Observer No 170, June/July: 247-252.

Dodgson, $\mathrm{M}$ and Rothwell, $\mathrm{R}$

1994 The Handbook of Industrial Innovation. Cheltenham, UK : Elgar.

Etzkowitz, $\mathrm{H}$ and Leydesdorff, $\mathrm{L}$

1995 "The triple helix : university-industry-government relations - a laboratory for knowledge-based economic development". EASST Review 14, 1: 14-19.

Europa World Year Book

1995 The Europa World Year Book, Vols I and II, Europe Publications Ltd.

Holecek, M, Rubin, J Strida, M and Gotz, A

1995 The Czech Republic in Brief. Prague: Publishing House of the Czech Geographical Society.

Johnston, $\mathrm{R}$

1996 "The new drivers of innovation in the knowledge economy", pp 229-240 in Sheehan, P et al (eds). Dialogues on Australia's Future. Melbourne : Victoria University of Technology, Centre for Strategic Economic Studies.

Kaukonen, E

1994 "Science and technology in Russia : collapse or new dynamics?". Science Studies 7, 2: 23-36.

Marceau, J

1996 "Refashioning industry policies : let's use what we know", pp 199-213 in Sheehan, $P$ et al (eds). Dialogues on Australia's Future. Melbourne : Victoria University of Technology, Centre for Strategic Economic Studies. 
Müller, K

1995a "Transformation of national research systems in the countries of central

Eastern Europe". Science Studies 8, 2: 44-55.

1995 b "Changes on the "borderlines" between research and industry following economic transformation in the Czech Republic". Social Studies of Science 12: 805-828.

1996 "Pattern of de-institutionalising a push-oriented national system of innovation". Unpublished paper presented at Triple Helix Conference, Amsterdam.

Nuclear Research Institute

1995 Annual Report - Nuclear Research Institute Czech Republic, Prague.

Provaznik, St, Filacek, A, Krizova-Frydova, E, Loudin, J and Machleidt, P

199 "The transformation of the research system in the Czech Republic".

Science, Technology and Society 1, 2: $311-331$.

Tegart, G

1990 "Strategic national priorities and internationalisation - Australia", pp 247-252 in Cozzens, $S$ et al (eds). The research system in transition.

Dordrecht : Kluwer Academic Publishers.

1996 "The co-operative research centres program : an Australian initiative to link research to commercialisation". Industry and Higher Education 10, 3: 150-169.

Greg Tegart

Australian Network for Research

and Technology Policy

University of Canberra

Belconnen, Australia 